recognised. As such she is restricted to reception duties, which is sad for us, since she is an excellent nurse, and sad for her, after she has clearly shown such commitment.

During the changeover period, this qualification would have resulted in automatic admittance to the new register. At the time there was much advertising of the changes in the dental press, but if you are off work raising a family, how were you supposed to know? Surely there should have been an obligation, by the registering body, to write to all of those who held the National Certificate, to alert them to the changes, so that this unfortunate dilemma could have been prevented.

Clearly, it is unreasonable to expect people in this position to embark on training again, whilst also having domestic commitments. It seems so unfair to someone who has tried so hard to achieve a qualification; is it not possible to find a way to accept these nurses onto the register?

I first raised this unhappy situation with the General Dental Council over a year ago and despite reassurance that the registration department would consider the matter, I have heard nothing.

C. Barber, Poynton

1. Marks C. Barred from consideration. Br Dent J 2012; 213: 264-265.

DOI: 10.1038/sj.bdj.2013.3

\section{PLENTY AND SCARCITY}

Sir, the Kerala state branch of the Indian Dental Association called for a one day dentist strike on 23 July 2012 to protest against the opening of new dental colleges in the state. ${ }^{1}$ From just two in the year 2000, the number of colleges in Kerala has increased to 23 in 2012. ${ }^{1}$ In addition, permission has been granted for 11 more dental colleges. In response, the government has agreed to cancel the 'essentiality certificate' granted to the colleges.

The dentist-to-population ratio in the state is currently $1: 3,300$ whereas the WHO recommended ratio is $1: 7,500$. The projected ratio in 2020 is $1: 1,500$ and in 2030 is 1:733. In 2011, over 1,400 students were admitted into the dental colleges of Kerala. ${ }^{2}$ The private sector remains the major employment provider for these graduates as the total existing job opportunities in government is 243 of which 144 are in government run dental colleges. ${ }^{1}$

The demand for dental treatment in Kerala is high owing to a low dentistto-population ratio and increased awareness among the population.

Many dentists prefer to live in urban areas, although some do not practise dentistry. ${ }^{2}$ The private practice sector in these cities has become saturated whereas the majority of rural populations do not have access to primary dental care. ${ }^{3}$ This co-existence of plenty and scarcity simultaneously makes it likely that dentist protests like that in Kerala may happen in other parts of India in the near future. Geographic imbalances among the location of dental colleges also contribute to this variation. The number of graduating dental students in India was 26,000 in the year 2000. ${ }^{3}$ With more than 280 colleges across the country, this number will definitely be higher now.

A moratorium against further opening of dental schools and enhancement of seats should be enforced. Increasing and maintaining the quality rather than quantity should be the priority. Increasing the number of postgraduate places would be desirable. An indiscriminate increase in the number of undergraduate places should be curbed. Along with the currently existing primary medical centres in every district, dental wings should be opened. That will facilitate delivery of primary dental care to rural population, increased oral health awareness and increased employment opportunities for dentists in the government sector which in turn would attract them to work in rural areas.

S. Thomas

By email

1. Indian Dental Association. Kerala State Branch. STATE WIDE STRIKE ON 23/07/2012 MONDAY. Available at: www.idakochi.org/activities/IDAStrikeLetter23-07-12.pdf.

2. Paul G. R Ahmed oration. 2012. Available at: www slideshare.net/maxfaxgp/excerpts-of-r-ahmedoration-george-paul (Accessed 18/08/2012).

3. Tandon S. Challenges to the oral health workforce in India. J Dent Educ 2004; 68 (7 Suppl): 28-33.

DOI: 10.1038/sj.bdj.2013.4

\section{WARFARIN PARADOX}

Sir, I would like to add to the recent letters in the $B D J$ on warfarin for the prevention of thrombo-embolic events in patients with nonvalvular atrial fibrillation and in adult patients who have undergone elective joint replacement surgery. ${ }^{1,2}$ A relatively recent newcomer in this field is the drug Pradaxa (dabigatran etexilate). A distinct advantage of this drug over warfarin is that it does not routinely require coagulation monitoring and initial use suggests that it may well quickly supersede warfarin.

Dabigatran etexilate is an oral, thrombin inhibitor with a linear doseeffect relationship and a predictable decline of anticoagulant activity. There is a clear correlation between plasma dabigatran concentration and degree of anticoagulant effect. Efficacy of anticoagulant action occurs in parallel with its elimination and, because it is eliminated unchanged by the kidneys, clearance of dabigatran in patients with impaired renal function may take longer. Plasma concentrations of dabigatran show a biexponential decline with a half-life of 12-14 hours.

In terms of coagulation assays, the activated partial thromboplastin time (aPTT) provides an approximation of the anticoagulation activity achieved with dabigatran, however, the aPTT test has limited sensitivity and is not suitable for precise quantification of anticoagulant effect. If required, more sensitive quantitative tests such as the calibrated diluted Thrombin Time (dTT) should be performed. Prothrombin time (INR) is not sufficiently sensitive and its use is not recommended.

As yet, there is no available protocol during dental surgery. Patients on dabigatran who undergo dental surgery, including dental extractions, are at increased risk of post-operative bleeding and to reduce the risk of bleeding, surgical interventions may require the temporary discontinuation of dabigatran. Caution should be exercised when drug treatment is temporarily discontinued especially as the patient will have concomitant medical problems and surgery should be delayed if possible until at least 12-14 hours after the last dose. If surgery cannot be delayed the risk of bleeding needs to be weighed against the urgency of intervention as the drug has no specific antidote. 